\title{
La reconstrucción del hecho en el Proceso penal en México
}

\author{
Rafael Santacruz Lima* \\ Recibido: 25 de Mayo \\ Dictaminado: 20 de Agosto
}

\begin{abstract}
Resumen correcta argumentación y ponderación de los hechos.

Palabras clave: Hecho, Reconstrucción, Prueba, Derechos Humanos.

\section{The Reconstruction of the fact in the criminal process in Mexico}

En el presente artículo se realiza un análisis en torno a la reconstrucción del hecho delictuoso en México, bajo el entendido que existen dos formas de reconstruir hechos del pasado en el proceso penal, lo que constituye seguir una serie de requisitos y formalidades establecidas en el ordenamiento jurídico, los cuales deben buscar en todo momento el respeto de los derechos humanos de las partes en el proceso penal; lo anterior se logrará si existe una

\begin{abstract}
This article analyzes the reconstruction of the crime in Mexico, under the understanding that there are two ways of reconstructing facts from the past in the criminal process, which is to follow a series of requirements and formalities established in the legal system Which must seek at all times to respect the human rights of the parties to the criminal process; This will be achieved if there is a correct argumentation and weighting of the facts.

Key words: Fact, Reconstruction, Proof, Human Rights.
\end{abstract}

\section{Sumario}

I Introducción; II Hecho y reconstrucción; III La verdad en el proceso penal; IV La

\footnotetext{
*Profesor-investigador Universidad Autónoma del Estado de México. rsantacruzl@uaemex.mx
} 
ponderación de los hechos en el proceso penal; V Sistema acusatorio y reconstrucción del hecho en México; VI Conclusiones; Bibliografía

\section{Introducción}

La reconstrucción del hecho delictuoso en el proceso penal, tiene como base fundamental establecer hechos pasados y en averiguar cómo sucedieron, y en determinar el caso sub judice; y también, en encontrar cuál es la ley que rige el caso.

Es por ello, que la reconstrucción del hecho, debe realizarse en el contexto de valores fundamentales que se han introducido en los ordenamientos jurídicos; valores que se han plasmado a través de los derechos humanos, los cuales se debe respetar de manera igualitaria.

En México, se implementó un sistema acusatorio-adversarial, con la reforma constitucional del dieciocho de junio del año dos mil ocho en materia de Justicia Penal y Seguridad Pública, la cual originó que el cinco de marzo de dos mil catorce, se publicara en el Diario Oficial de la Federación, el Código Nacional de Procedimientos Penales, mismo que estableció en su artículo 259 que: "Cualquier hecho puede ser probado por cualquier medio, siempre y cuando sea licito”.

Dentro de dichas reformas se desarrolló una serie de principios que deben seguirse durante la aplicación y desarrollo del sistema acusatorio, y por supuesto cuando se tenga que reconstruir el hecho delictuoso; sin embargo, también se plantea la posibilidad de establecer de manera excepcional, principios que deben regir la investigación de hechos presuntamente estimados como delitos, en materia de delincuencia organizada, lo que genera una cierta contradicción con los principios del sistema acusatorio.

Por lo tanto, se plantea la siguiente suposición o hipótesis, en México, se presentan dos formas diferentes de reconstruir el hecho delictuoso, por un lado, cuando se inserte dentro del sistema acusatorio; y dos, cuando se trate de delincuencia organizada. En tal sentido, si se presentan estas dos formas, el proceso penal, se legitimará en la medida en que sea capaz de lograr una correcta reconstrucción del hecho delictivo. Dicha reconstrucción, se debe alcanzar bajo 
una serie de pasos que aseguren la mayor racionalidad y eficacia de las distintas etapas del proceso. No se trata en esa virtud, de alcanzarla a toda costa, si así fuera, la prioridad seria la razón del Estado sobre la razón jurídica, originando con ello un sistema autoritario e inquisitivo.

Con lo anterior, se prende realizar un estudio descriptivo, que permita establecer la reconstrucción del hecho, bajo el entendido que, se debe realizar respetando los derechos de los actores en el proceso penal, bajo una correcta ponderación y argumentación de los hechos y pruebas; lo anterior, mediante un método analítico y deductivo, que nos permita explicar porque el proceso penal en un Estado democrático, tiene por objetivo y finalidad garantizar los derechos y libertades de los ciudadanos, otorgando un máximo de seguridad jurídica y un mínimo de violencia. Sin estos derechos y garantías, todo Estado se pone en tela de juicio, y sus actuaciones pueden caer en el autoritarismo y represión.

\section{Hecho y reconstrucción material}

Del delito y sus circunstancias lo mejor que tenemos es un conjunto de versiones acerca de lo que "realmente ocurrió", el imputado tiene una versión, la víctima tiene la suya, la policía hace lo propio y lo mismo cada uno de los testigos. En ocasiones se trata de versiones completas, en ocasiones se trata de versiones parciales; en ocasiones dichas versiones se construyen sobre la base de la información (Baytelman, 2009: 80).

El hecho delictivo es, el acontecimiento que se adecúa a la norma penal abstracta -delito- que se obtiene a través del proceso cognoscitivo que evidencie la necesaria vinculación entre polos sustantivos y dogmáticos con el proceso penal. Cuando los jueces fallan construyen una versión acerca de lo que "verdaderamente ocurrió" y aceptamos esa versión como la versión oficial, en ciertos casos, adoptando la versión de una de las partes, o en su momento, tomando porciones de las versiones de cada una de las partes. Pero desde luego, nadie pudiera comprender que cuando el juez dicta una sentencia ella ha descubierto necesariamente la verdad (Baytelman, 2009: 80). 
De tal forma, los hechos mediante el razonamiento judicial, suele reflejar una consideración de los mismos como constructos naturales, previa y definitivamente constituidos desde el momento de la producción, que sólo se trataría de identificar en su historial (Andrés, 2015: 49). Siendo así, se intuye fácilmente que no se puede hablar del hecho separándolo completamente del derecho u olvidando sus implicaciones jurídicas. Con esto no se pretende hacer referencia aquí a toda la problemática tradicional, en muchos aspectos agotada, de las relaciones entre el hecho y el derecho (Taruffo, 2011: 46).

En tal sentido, es necesario tener presente un factor importante: en el proceso penal, los hechos de los que hay que establecer la verdad, son identificados sobre la descripción que realiza la norma jurídica, representados esencialmente por las leyes que se consideran aplicables para decidir la controversia específica. Para usar una fórmula sintética: "Es el derecho el que define y determina lo que en el proceso constituye el hecho". ${ }^{1}$

Por lo tanto, no debe confundirse entre el hecho y derecho, ni mucho menos a quitarle autonomía al hecho para diluirlo y anularlo en la estructura jurídica de la controversia. Así pues, resulta poco provechoso realizar la distinción hecho y derecho, sino que hay que tomar en consideración las distintas modalidades con las que el hecho, destinado a constituir el objeto y la finalidad de la prueba, es identificando a través de las normas aplicables al caso específico (Taruffo, 2011: 46).

De tal modo, que reconstruir implica por un lado, comprobar la realidad de un hecho, que éste efectivamente tuvo lugar en la realidad y no sólo en la mente de quien lo narra, esto es, que la forma en que ocurrieron los hechos coincida y se equipare a la presentada en el relato, y, por otro lado, que esa narración, la cual contiene un versión real que coincida y que pueda ser subsumida en la que está descrita en el tipo penal que se invoca (Natarén, 2011: 117).

La búsqueda de la verdad sobre los hechos que se presentan ante el órgano jurisdiccional, el llamado fin inmediato de proceso, será desarrollado teniendo como sustento a la reconstrucción conceptual de aquéllos. La prueba es el medio más seguro para lograr una reconstrucción del hecho de modo comprobable y

1 El hecho, por tanto, no está todo por sí mismo y autónomamente antes de que asuma relevancia jurídica. En el proceso es hecho lo que se define como tal en fundación de la norma aplicable para decidir la controversia. 
demostrable, pues la inducirá de los rostros o huellas que los hechos pudieron haber dejado en cosas o personas, o de los resultados de experimentación o de inferencias racionales sobre tales rastros o huellas (Cafferata, 2008: 5).

El contexto de la decisión, como esquema de referencia, en función del cual se define el hecho como objeto de la prueba, permite determinar dos perspectivas de definición del hecho, distintas pero convergentes precisamente hacia la individualización de lo que constituye el objeto de la prueba (Taruffo, 2011: 96). En ese entendido, y siguiendo las ideas de Taruffo, la primera perspectiva está referida directamente al contexto de la decisión, en el sentido de que se obtiene de él las coordenadas que definen teóricamente el objeto de la prueba. La segunda perspectiva está referida a las modalidades mediante las que el objeto de la prueba es concretamente individualizado y fijado en el proceso en referencia al concreto supuesto de hecho controvertido (Taruffo, 2011: 96).

De tal manera que, desde esta perspectiva, el contexto de referencia es también la decisión específica que deberá ser tomada por el juez, pero es sobre todo el procedimiento que concluye con la decisión y que comprende la deducción, la admisión y la asunción de pruebas. Podemos considerar que la primera perspectiva, en cierta forma son distintas, sin embargo, tienen una finalidad que es producir o recaer en la decisión. Por lo tanto, podemos considerar que la primera perspectiva, que hace alusión a la decisión, realiza un estudio y análisis del hecho desde un punto de vista teórico de la prueba; mientras que la segunda, que se enfoca al enjuiciamiento como tal, está referida en esencia al objeto de la prueba.

Luego entonces, de lo anteriormente descrito, se puede llegar a establecer que la prueba, se legitima siempre que tenga como objetivo la búsqueda de la verdad del hecho presuntamente estimado como delito, que conoce el órgano jurisdiccional. Por ello, es importante dejar claro que, la prueba busca como finalidad fundamentar la reconstrucción del hecho en el proceso.

En ese tenor de ideas, la prueba debe servir y establecer coherencia con el relato, es decir, con la opinión y descripción de lo que realmente ocurrió. De esta aseveración podemos decir que, establecer que la prueba es un elemento del enjuiciamiento, que habla por sí solo, es una idea de corte inquisitivo, ya que en dicho sistema, la prueba bastaba con ser ofrecida para que cumpliera con su 
finalidad, es decir, que "hablaba por si sola".

La carencia de prueba y la negligencia o impericia en obtenerla, frustran el deber de perseguir e impiden la función de juzgar. Se habría enrarecido, merced a la impunidad -procurada o no-, una de las misiones nucleares del Estado. Los sujetos que intervienen en el enjuiciamiento, tiene la responsabilidad de probar sus versiones, lo mismo cuando atribuyen que cuando rechazan, así el fiscal y el inculpado, y en su propia hipótesis el ofendido que reclama el resarcimiento (Ribeiro, 2006: 26).

La verdad ha sido, históricamente, una condición necesaria del proceso judicial. El objeto de disputa del proceso judicial es la propuesta de versión que cada una de los sujetos en el enjuiciamiento propone (Ribeiro, 2006: 26). La verdad históricamente ha tenido muchas formas de presentarse en el proceso judicial. Cada una de las versiones que se someten al órgano jurisdiccional, también están condicionadas al tiempo y a su cultura. Esto quiere decir que las formas de presentarse la verdad no ha sido un concepto inmutable así como la idea de verdad misma.

En tal sentido, cuando se plantea una controversia ante el órgano jurisdiccional, se busca que los jueces realicen dos tareas diferentes, es decir, busca valorar y establecer hechos pasados, y a partir de los elementos planteados conocer cómo sucedieron, en determinar el caso sub judice. La segunda tarea consiste en encontrar cuál es la ley que rige el caso, cuáles son las disposiciones legales que desatan el nudo gordiano de la cuestión, dando razón al nudo, quitándosela al otro. ${ }^{2}$

De tal manera que, el debate en torno a la actividad probatoria del juzgador; no hay duda sobre la obligación que tiene de realizar una función cognitiva que en ocasiones no podrían aportar los actores en el enjuiciamiento. Por lo tanto, surge una pregunta: ¿Puede el juez, bajo el régimen acusatorio, indagar los hechos por su cuenta con el propósito de conocer la verdad, que de otra suerte -y así lo

\footnotetext{
2 Las distintas concepciones que existen acerca del problema de la determinación de la verdad en el proceso no puede dejar de incidir en la forma de entender la prueba. Por una parte, en efecto, algunas de ellas implican que se ponga en discusión la relación de medio a fin que usualmente se identifica en la conexión entre prueba y verdad judicial; por otra parte, incluso cuando no se rechaza esa relación, las redefiniciones del fin, es decir, de la verdad judicial, tienen inevitables efectos sobre la forma de entender el medio, esto es, la prueba.
} 
percibe el tribunal- quedaría en penumbra? ¿Podría, en tal virtud, recuperar la función de inquirir, a riesgo de empañar la misión de juzgar? ¿O sucedería, más bien, que para iluminar ésta se verá en la necesidad de asumir aquélla? ${ }^{3}$

Luego entonces, en el modelo de sistema acusatorio, el juez debiera conformarse con la prueba que las partes le suministran, aunque se establezcaporque el tribunal no es ciego- que la reconstrucción consista en un error, lo que originaría, como consecuencia, una injusticia. Por lo tanto, en un modelo de justicia inquisitivo, se entendería que el juez, si desaparece por sí mismo la sombra que le impide caminar en procuración de la verdad y hacer, en último análisis justicia.

Es por ello que, y como sostiene Ferrajoli, en contraste con otros poderes públicos, el poder judicial no admite una legitimación de tipo representativo o mayoritaria, sino sólo de tipo racional y legal. No puede castigarse a un ciudadano sólo porque ello responda a la voluntad o al interés de la plenamente alcanzable, sino sólo aproximable a causa de los límites intrínsecos de los criterios de comprobación de la verdad procesal de los hechos sucedidos, y del razonamiento que hagan los tribunales a través de los jueces (Ferrajoli, 2004: 237).

\section{La verdad en el proceso penal}

La verdad es un ejercicio cognitivo, es decir, que es la construcción de un consenso racional, desde Rorty, se puede afirmar que la construcción de la verdad es siempre una construcción lingüística, porque hay verdades toda vez que es una propiedad de los enunciados, porque la existencia de los enunciados depende de los léxicos, y porque los léxicos son realizados por los seres humanos (Rorty, 1991: 41).

La verdad tiene muchas formas de presentarse, y para ser más específicos, en el enjuiciamiento penal porque aunque existan tipos normativos ya descritos, la realidad hace único e irrepetible al hecho. Cada una de las formas de presentarse

\footnotetext{
3 Ferrajoli establece: "En un Estado de derecho la actividad jurisdiccional, es una actividad cognoscitiva además de práctica y prescriptiva, requiere, como justificación de las decisiones en las que se expresa, una motivación de la aceptación de sus presupuestos como verdaderos, aunque sea en el sentido relativo y aproximativo".
} 
la verdad en el proceso judicial está condicionada por la cultura de su época. Esto quiere decir que las formas de presentarse la verdad no ha sido un concepto alterado así como la idea de verdad misma. ${ }^{4}$

Pero si la verdad es una construcción, entonces las modalidades de presentarse será la edificación de enunciados que sustenta una serie de ideas lógicas, racionales, razonables y lingüísticas de las diferentes narraciones. ${ }^{5} \mathrm{La}$ concepción semántica de la verdad procesal como correspondencia, Luigi Ferrajoli considera, más fuerte a la jurisdicción penal, donde el nexo exigido por el principio de estricta legalidad entre la validez de la decisión y la verdad de la motivación, que en cualquier otro tipo de actividad jurisdiccional (Ferrajoli, 2011: 47).

La verdad en el proceso judicial encuentra su modernidad con Descartes. El problema de la verdad por primera vez rebasa la idea de que la verdad se descubre o se encuentra por medio de Dios o por medio de los sentidos. Dos recursos formales por medio de los cuales se presentó históricamente la verdad. Frente al engaño de los sentidos, surge la duda como método de trabajo, como proceso formal por medio del cual se puede descubrir la verdad (Ferrajoli, 2011: 47)

De tal modo entonces, que la verdad como comprensión es, a un tiempo, una interpretación y un movimiento argumentativo entre la tradición y el intérprete, es decir, para nuestro caso, una interpretación entre la tradición del corpus jurídico y el movimiento del intérprete de la tríada procesal. En este diálogo creador, argumentativos de la verdad, se ponen en movimiento la tradición legislativa del corpus jurídico y la tradición teórica del intérprete (Ribeiro, 2006: 39).

Hay al menos dos tipos de razones por las que el concepto de verdad de los hechos en el proceso, produce relevantes dificultades e incertidumbres en la función que tiene la prueba en el proceso. El primer tipo hace referencia a la relación que se establece entre la idea de una verdad "judicial" o "procesal" especial y la

\footnotetext{
4 La verdad y sus formas cambian históricamente de acuerdo a las significaciones temporales. Así, si la verdad es una condición inherente a Dios, la forma de presentarse la verdad en el proceso judicial será la del reconocimiento de Dios una u otra verdad propuesta. Pero si la verdad se descubre desde la racionalidad científica, entonces la forma de presentarse esa verdad será desde las periciales, desde las pruebas científicas y tecnológicas.

5 Narraciones en primera persona del indiciado, narraciones en tercera personas desde las testimoniales, narraciones explicativas desde los informes médicos y las periciales, etc.
} 
idea o las ideas que se tienen de verdad fuera del proceso. Esencialmente, se trata de saber si hay identidad entre estas concepciones de la verdad o bien si la verdad que se desarrolla en el proceso en específico, en tal caso, cuáles son las razones de ello y las formas en que aquéllas es particular (Taruffo, 2011: 24).

Luego entonces, la verdad de proposiciones que describen sucesos de la realidad, es decir, casos facticos, no puede evitarse, ni siquiera en los casos de modelos científicos ya establecidos. Cuando nuestros procesos de razonamiento sufran de algunas limitaciones, no es pretexto para exentar a la prueba jurídica, y más técnicamente, a la decisión sobre los hechos basada en las pruebas, de la aplicación de elementos y reglas de la racionalidad general.

De tal forma, como dice Ferrajoli, el juicio penal como saber-poder, encuentra la oposición hasta ahora ilustrada entre garantismo y autoritarismo en el derecho penal corresponde, pues, a una alternativa entre dos epistemologías judiciales distintas: entre cognoscitivismo y decisionismo, entre comprobación y valoración, entre prueba e inquisición, entre razón y voluntad, entre verdad y potestad. Si una justicia penal completamente "con verdad" constituye una utopía, una justicia penal completamente "sin verdad" equivale a un sistema de arbitrariedad (Ferrajoli, 2011: 45).

En ese entendido, el juicio penal, es por excelencia una actividad racional, es decir, una combinación de conocimiento y decisión. La decisión, más en general, de cualquier discurso jurídico justificativo, es una verdad no definitiva sino continente, no completa sino relativa al estado de los conocimientos y experiencias llevadas a cabo en orden a los hechos de que se dirimen: de modo que, siempre, cuando se afirma la verdad de una o varias proposiciones, lo único que se dice es que éstas son (plausiblemente) verdaderas por lo que sabemos, o sea, respecto del conjunto de los conocimientos confirmados que poseemos.

Para alcanzar la verdad en el proceso penal, y en cada circunstancia del hecho fáctico, se puede muy bien usar la noción sugerida por Popper, de aproximación o acercamiento a la verdad objetiva, entendida ésta como un modelo estándar que nos permite acercar, sin igualar a la realidad, y tenga como papel de un principio regulativo que nos permite aseverar que una tesis o una teoría son más plausibles o más aproximativamente verdaderas y, por tanto, preferibles a otra por causas de 
su mayor poder de explicación y de los controles más numerosos favorablemente superados por ella (Ferrajoli, 2011: 50).

Por lo tanto, y siendo el objetivo principal, en el juicio penal, averiguar la verdad acerca de la comisión de un hecho delictuoso (Laudan, 2013, p. 96). Tal aseveración, permite establecer que en el enjuiciamiento penal, se debe analizar y ponderar la forma de obtención de la prueba, su admisión y relación que guarda con el nexo causal, hasta la necesidad y valoración de las mismas. ${ }^{6}$ En ese entendido, el desarrollo de la prueba, como búsqueda de la verdad, debe realizarse bajo estándares que operarán en un proceso penal, siempre teniendo como objeto principal, el respeto de los derechos humanos.

De tal forma, que la verdad o la búsqueda de la verdad en un proceso jurídico-penal es una finalidad que se persigue ${ }^{7}$ y que se puede conjugar con diversos medios y fuentes para su obtención, ${ }^{8}$ como lo puede ser, con el principio de contradicción y demás principios con el conocimiento e imparcialidad del juzgador, como motor en la búsqueda de una motivación racional, y razonable, donde se persiga un equilibrio entre la búsqueda de la verdad tutelando la dignidad del acusado y la participación de la víctima, sin que se persiga una verdad absoluta sino el deber de apoyar una condena sólo sobre aquello que indubitada e intersubjetivamente puede darse como probado. Lo demás es puro fascismo y la vuelta a los tiempos de la inquisición, de los que se supone ya hemos salido (Muñoz, 2007: 120).

La intervención de las partes en este punto tiene particular importancia, puesto que, hace posible que defiendan sus propios intereses, que no necesariamente

\footnotetext{
6 Por poner un ejemplo, dos pruebas periciales podrían tener diversos márgenes de error, dependiendo las técnicas empleadas, ya no se diga la valoración de las mismas, que podría variar hasta por el desconocimiento de las técnicas que se emplean en su obtención. Por lo que pueden ser consideradas, ambas pruebas o todas las pruebas hasta las ordinarias, parte de lo que se persigue con el motor en la búsqueda de la misma.

7 Se puede decir que la verdad, es aquélla que se pretende obtener del análisis de lo ofrecido al proceso, como resultado de la actividad probatoria, pudiendo o no coincidir con la verdad histórica, pero sobresaliendo o gozando de autoridad y consecuencias jurídicas, ya que independientemente de su coincidencia, se calificarán de verdad los hechos probados y valorados, como jurídicamente relevantes durante el mismo.

8 Se puede decir que la verdad, es aquélla que se pretende obtener del análisis de lo ofrecido al proceso, como resultado de la actividad probatoria, pudiendo o no coincidir con la verdad histórica, pero sobresaliendo o gozando de autoridad y consecuencias jurídicas, ya que independientemente de su coincidencia, se calificarán de verdad los hechos probados y valorados, como jurídicamente relevantes durante el mismo.
} 
tienen que coincidir con el descubrimiento de la verdad. Esta defensa puede suponer perfectamente la manipulación del material probatorio. La posibilidad de que el juez ordene la práctica de pruebas no solicitadas por las partes, en los procesos puede contribuir a paliar es problema, como también se aduce, que con el uso de la contradicción se pueda contribuir a ello, al escuchar a las partes y detectar márgenes de error o de disfunción en las pruebas.

Por lo cual, en el proceso se precisa la tutela de los derechos fundamentales por las autoridades sean municipales, locales o federales, para un equilibrio entre los sujetos procesales, con lo que se permita llegar a una justicia más humana, basada en una argumentación racional y razonable que se refleje en una resolución judicial, es por ello, la trascendencia de posibilitar el contradictorio como método (el cual no es exclusivo del sistema procesal penal acusatorio), que se siga tutelando desde la acusación y hasta el posible juicio oral, donde se pudieran poner en discusión las diferentes tesis formadas y formuladas por la fiscalía y la defensa en la exposición de su teoría del caso, con lo que deberá discernir e interpretar el juzgador, basado en razones jurídicas, hechos y pruebas allegadas integralmente, para llegar con ello, a la valoración del caso en particular, en la búsqueda de una verdad jurídica racional y razonable, lo más acercada a valores.

\section{La ponderación de los hechos en el proceso penal}

Los jueces, dentro de su actividad, tienen la función de valorar pruebas, ya que constituye la operación mental mediante la cual el juzgador evalúa el poder de firmeza de los elementos probatorios que han sido admitidos en el proceso y que le son necesarios para justificar la resolución que adjudicará la controversia. (Bassat, 2007: 66).. Lo anterior, nos permite establecer que la prueba produce convicción en el juez a fin de establecer por qué sucedió el hecho delictuoso. ${ }^{9}$

\footnotetext{
9 Debemos tener presente que la valoración de la prueba es efectuada por el Juez, quien debe tener presente tres aspectos, en primer lugar tendrá que percibir los hechos a través de los medios probatorios,. En segundo lugar, el Juez deberá efectuar una representación o reconstrucción histórica de los hechos en su conjunto, en este caso además de utilizar los medios directos puede emplear los medios indirectos, los cuales sólo proporcionan datos, a partir de los cuales el Juez elabora un argumento para deducir la existencia de un hecho, como ocurre con los
} 
En proceso penal, el juez debe aspirar a conocer la verdad en el caso concreto, para conseguir el esclarecimiento del hecho delictuoso. Luego entonces, los jueces, en el proceso penal, requieren de una vasta cultura o dominio de alguna área disciplinaria, así como una gran capacidad para construir textos lógicos y coherentes, con la utilización de arsenales y recursos argumentativos (Galindo, 2010: 54).

De tal manera, que la actividad de juzgar en materia penal, valorar y ponderar, se caracterizan por el análisis conjunto de lo realizado en la investigación, para así, obtener un resultado, en cuanto a la conducta o hecho. De ahí que los indicios, del hecho delictuoso, tienen una gran importancia desde su localización hasta su valoración por los órganos jurisdiccionales, porque serán objeto de una ponderación, por lo tanto, los jueces no pueden viciar el manejo de ellos, para evitar alteraciones (González, 2003: 349).

Por lo tanto, en la actividad de juzgar, existen elementos persuasivos en la asunción de las pruebas al proceso penal, es decir, un factor importante no sólo es establecer si esos hechos existieron, sino también, si son importantes como para justificar una retórica de la prueba que pueda ser asumida como convincente. Es en este plano, donde la prueba encuentra su desarrollo como argumento persuasivo, y por ende, objeto de ponderación. ${ }^{10}$

No es casualidad que la prueba se sitúe en el discurso retórico, porque cuando las partes tratan de convencer al juez, de ahí que dicho discurso se dirige al intelecto, al juicio, al conocimiento o sentido común para aceptar la validez de ciertas aseveraciones. El discurso convincente de los actores en el proceso penal, debe dirigirse a la razón por medio de argumentos racionales fundados en Derecho y en pruebas sobre hechos expuestos con claridad y precisión en sus alegatos. Este efecto de la argumentación, más racional, se presenta en el discurso de los jueces, apoyados en la lógica, en el derecho y en los datos objetivos que den sustento a sus decisiones.

\footnotetext{
indicios. En tercer lugar, el desarrollará una actividad analítica o de razonamiento mediante la cual se obtienen las inferencias de los datos percibidos.

10 Algunas de estas dificultades se refiere a la confirmación histórica de la teoría en cuestión, que encuentra límites relevantes. Por un lado, en efecto, no hay duda que en Grecia y en Roma existía una concepción "retórica" de la prueba como argumentación dirigida a persuadir al juez.
} 
Por lo tanto, en el proceso penal, se pretende obtener la verificación de todo un marco contextual formado por los hechos y la norma jurídica, y también, el convencimiento de que el juzgador debe hacerse de diversos procedimientos racionales en la estructuración de una resolución, como lo puede ser, con el uso de la ponderación o establecimiento del peso necesario en cuanto a valores o fines de principios y derechos cuando se encuentren en colisión, según la ley de la ponderación (Alexy, 2007: 32).

De tal suerte, una ponderación es racional, y en el proceso penal no es la excepción, si una resolución que tenga como objetivo resolver un hecho delictuoso, pueda ser fundamentada racionalmente (Alexy, 2007: 32). La reconstrucción del hecho delictuoso, por medio de la verdad en el proceso penal, debe asegurar la protección jurídica de los derechos fundamentales de los actores en el proceso penal, y se contribuya así a la optimización de su eficacia como principios, y lograr con ello, una correcta materialización de los derechos de las partes en el proceso penal. ${ }^{11}$

\section{Sistema acusatorio y reconstrucción del hecho en México}

La reforma penal en México del dieciocho de junio de dos mil ocho, tiene como uno de sus objetivos y finalidades que las partes sea confrontadas para saber la versión de lo que sucedió en el hecho delictuoso, a través de los actos de prueba que, durante la audiencia, realizarán, ya sea en las declaraciones de personas (acusado, testigos, víctima y peritos), o bien en la información documental y/o material, o por última extrayendo los datos de otras fuentes de prueba.

Aquí el juzgador entonces, cede a las partes el ofrecimiento y desahogo de las pruebas; siendo las partes quienes, a través de las estrategias de litigación

\footnotetext{
11 En este sentido Carlos Bernal Pulido, nos dice que la importancia de los principios en colisión no es la única variable relevante en la ponderación. La segunda es el "peso abstracto" de los principios. El peso abstracto de los principios puede variar de acuerdo con la jerarquía de la fuente del derecho en que estén establecidos...A lo anterior debe sumarse una tercera variable $\mathrm{S}$, que se refiere a la seguridad o certeza de las apreciaciones empíricas concernientes al grado en que la medida analizada implica fácticamente la falta de la satisfacción del primer principio y la satisfacción del segundo en las circunstancias del caso en concreto.
} 
oral, defenderán su versión y atacarán la de su contraparte. Pero esta actividad no consiste en una actividad de salir a pescar lo que se encuentre, por el contrario requiere de un ejercicio racional, razonable y prudente, para ello, para cada órgano de prueba, los sujetos en el enjuiciamiento, debe contar con una estrategia procesal, que le permita contar con los elementos de litigación oral. (Pastrana, 2009: 188).

Por lo tanto, la prueba es el conocimiento y resultado adquirido, a través de actividad de verificación procesal, del hecho presuntamente estimado como delito, la cual, en un sistema acusatorio como el caso de México, tendrá como principales actores a las partes, y su objeto será, a través de la confrontación y discusión, verificar la acusación en el juicio oral. De tal suerte que, la prueba emana de una información, es decir, sus fuentes son: personas (victima, testigos o peritos), lugares, objetos y documentos.

De tal manera, para cada órgano de prueba se debe contar con un planteamiento de reconstrucción de hechos, el cual siempre tendrá como brújula la acusación y la defensa, que tiene como objetivo al final de la audiencia, demostrar como válida, la creíble. Por ende, en la dinámica del Juicio (en el contexto de un proceso penal de corte acusatorio en México), las partes ya no deben esperar lo que el juez hará para con los órganos de prueba; sino que son ellos, por ser los interesados en demostrar su caso, los llamados a presentar un rol activo.

Uno de los grandes debates de la reforma Constitucional de dos mil ocho en México, en materia de Justicia Penal, es la incorporación del tipo penal de Delincuencia Organizada en el artículo dieciséis, párrafo noveno; generando una contradicción, ya que todo texto Constitucional debe enunciar principios, más no reglas propias de las normas secundarias, como los Códigos Penales.

De lo anterior, no es posible asumir sin objeciones la idea de que en México se tenga un modelo del todo acusatorio, en especial podemos identificar un modelo diferente, cuando se trata de delincuencia organizada, ya que carece de las más elementales garantías, por cuanto ha venido abarcando más la reconstrucción del hecho, en el ámbito de incriminación.

Por lo tanto, en delincuencia organizada, la prueba y la reconstrucción del hecho, al momento de ofrecerse, desahogarse y valorarse, no se sigue los 
principios rectores del sistema acusatorio adversarial; identificando dentro del enjuiciamiento reglas inquisitivas, que bien pueden identificarse con sistemas autoritarios. Peor aún, una de las críticas que se hacen a la reforma es precisamente que la investigación que realiza el Ministerio Público cuenta con un valor probatorio preponderante al momento de dictar sentencia.

Por eso, se puede admitir el supuesto de la prueba anticipada, cuyo desarrollo es diferente a la prueba que debe ser desahogada en la audiencia de juicio que sirva como fundamento de la sentencia. De tal manera que, el Constituyente, confronta al artículo 16 con el artículo 20 que entiende el proceso penal "acusatorio y oral" $\mathrm{y}$, consecuente bajo los "principios de publicidad, contradicción, concentración, continuidad e inmediación (Hidalgo, 2009: 214).

En tal sentido, podemos establecer que en el proceso penal en México, se sigue para la reconstrucción del hecho, dos formas diferentes. Por un lado, encontramos una reconstrucción basada en un sistema acusatorio-adversarial, y por la otra, una forma de reconstruir el hecho basado por un sistema de excepción, cuando se trate de delincuencia organizada.

Lo anterior, nos invita a realizar un análisis de un caso práctico, para poder soportar dicha aseveración:

"En la audiencia para el desahogo de prueba anticipada, del expediente $708 / 2015$, por el delito de secuestro en agravio de persona del sexo femenino de identidad reservada, celebrada el 08 de junio de 2015, en la sala 2 del Juzgado de control del Distrito Judicial de Toluca, residente en Almoloya. La petición por parte del Ministerio Público, para la celebración de la audiencia para el desahogo de la prueba anticipada, se solicitó bajo los siguientes elementos: a) La víctima cuenta con nacionalidad de los Estados Unidos de Norte América; b) Un certificado médico donde se describe estado gravidez de la víctima; c) Un boleto de avión, donde señala el nombre de la víctima, y fecha de vuelo con destino a los Estados Unidos de Norte América, d) Y la petición del consulado de los Estados Unidos, para que la víctima pueda dar a luz en dicho país. Con tales elementos el Juez de control aceptó el desahogo de la prueba anticipada” (Santacruz, 2015, p.122). 
Para poder analizar este caso práctico, el artículo 304 del Código Nacional de Procedimientos Penales, nos establece que:

"La prueba anticipada podrá ser solicitada por alguna de las partes, quienes deberán expresar las razones por las cuales el acto se debe realizar con anticipación a la audiencia de juicio a la que se pretende desahogar y se torna indispensable en virtud de que se estime probable que algún testigo no podrá concurrir a la audiencia de juicio, por vivir en el extranjero, por existir motivo que hiciere temer su muerte, o por su estado de salud o incapacidad fisica o mental que le impidiese declarar".

Por lo tanto, si analizamos la solicitud por parte del Ministerio Público, la prueba anticipada debe ser solicitada por alguna de las partes, en este caso, se cumple con dicho requisito, sin embargo, cuando establece que deben expresarse las razones, el Ministerio Público, no dio las razones justificadas para el desahogo de dicha prueba, es más, consideramos que el juez de control, no debió haber aceptado el desahogo de dicha prueba, toda vez, que la víctima no cuenta con sus domicilio en el extranjero, y el estado de gravidez no imposibilita a la víctima para que pueda concurrir a la audiencia de juicio a declarar con posterioridad.

Lo anterior, para que pueda lograrse un enjuiciamiento garantista, se debe realizar bajo las mismas prerrogativas, que permitan a los sujetos en el proceso, contar con las mismas oportunidades para aportar, ofrecer, materializar y desahogar las pruebas, y desde luego, para poderlas debatir. Si dentro del proceso penal se logran estas prerrogativas, se estaría hablando que se garantiza una igualdad entre las partes.

Se suponía que con el nuevo sistema de justicia penal solamente valdría lo que se reproduzca en un juicio oral, público y con el juez y las partes presentes, sin embargo, la reforma constitucional autoriza que las actuaciones realizadas en la fase de investigación tengan valor probatorio, lo que es criticable aun y cuando se trate de delincuencia organizada, pues ya no podemos hablar entonces de un sistema penal acusatorio, ya que es evidente que no cumple con los parámetros 
mínimos que se han establecido para ello. ${ }^{12}$

Para comprender, entonces, el rol que juega la reconstrucción del hecho, en el proceso penal en México, es fundamental recordar que uno de los postulados de la reforma de 2008, es evitar la inclinación hacia la escritura y, a la vez, sin embargo, cuando se trate de delincuencia organizada, se podrá tener registros escritos que permitan el .desahogo dela prueba en etapa de investigación, con la prueba anticipada.

Por lo tanto, cuando se hable de la prueba anticipada, se va generar un conflicto, porque no se establece, ni en la Constitución ni el Código Nacional de Procedimientos Penales, la diferencia entre concepto de "desahogo" de la prueba y "desahogo previo". De tal manera que, confunde" al referirse a la prueba anticipada del desahogo en audiencia de la prueba, o sin "comprender" que tanto la prueba que se desahoga en juicio como la que se desahoga fuera de juicio es, en definitiva, desahogada en audiencia. ${ }^{13}$

En tal sentido, si comprendemos el objetivo de la investigación que conlleva al hallazgo, acopio, identificación y traslado de las evidencias; indicios que conforman los datos de prueba; con los medios de prueba que se producen, en virtud de esos datos de prueba, y que han de ser desahogados, en tutela de los principios de inmediación y contradicción (Hidalgo, 2009, p. 214). Nos permite establecer que, dichos elementos busca con ello la reconstrucción del hecho delictuoso, sin que ello pueda hacer excepciones, como en el caso de la prueba anticipada.

De tal manera, que los hechos que sean reconstruidos en la investigación, deben seguir una serie de pasos que busquen garantizar los derechos de los sujetos en el proceso penal, lo que permita una defensa técnica del imputado, y una acusación correcta por parte del Ministerio Público, mediante los datos que consten el proceso, siempre siguiendo una correcta igualdad entre las partes.

En este tenor de ideas, se puede establecer que, la reconstrucción del hecho,

12 Los parámetros probatorios potencialmente podría implicar, en la práctica, una disminución significativa de los derechos de los ciudadanos; por esta razón, puede afirmarse que la regulación adecuada de la vinculación a proceso constituye una de las cuestiones más delicadas al trasladar los preceptos constitucionales a la legislación secundaria.

13 Considero que, aun cuando la prueba anticipada ingrese al juicio como acta, como registro o como video, no se presentan en su totalidad los principios de inmediación y contradicción, que exige el sistema acusatorio. 
en materia de delincuencia organizada, se requiere de una correcta ponderación y argumentación por parte del juez, ya que no se seguirán, o no se presentará en su totalidad, los principios del sistema acusatorio, en especial del principio de contradicción e inmediación en la audiencia final de juicio.

\section{Conclusiones}

A manera de consideraciones finales, podemos decir que, para lograr un respeto de los derechos en la reconstrucción del hecho, se requiere que exista una correcta argumentación jurídica, sustentada en la ponderación. En México, como vimos en el presente artículo, existen dos formas diferentes de reconstruir el hecho delictuoso; una basada por principios de un sistema garantista; y otra desarrollada por un sistema de excepción, cuando se trate de delincuencia organizada. En tal sentido, podemos aseverar que, en relación a la hipótesis plateada al inicio, se comprueba las dos formas de reconstrucción del hecho, y se pone en evidencia la vulneración de los derechos humanos, cuando se trate de delincuencia organizada, porque no se siguen los princios del sistema acusatorio-adversarial.

En ese tenor, cuando los jueces resuelven en un proceso penal, también de cierta forma, reconstruyen una versión de lo sucedido en el hecho delictuoso, y se acepta esa versión como la versión oficial, en ocasiones hacen esto adoptando completamente la versión de una de las partes, en ocasiones lo hacen tomando porciones de las narraciones y aseveraciones de los sujetos que intervienen en el proceso penal.

De tal manera que, la sentencia judicial de los hechos en el proceso penal, se sitúa en el interior de la decisión judicial y la prueba está dirigida a la determinación de la verdad, o por lo menos, en la búsqueda de la misma. De esta aseveración, se deriva que el objeto apropiado de la prueba es el hecho que debe ser reconstruido y determinado, es decir, el hecho que es objeto de la decisión. Por lo tanto, para que se pueda realizar dicha decisión en el proceso penal, se necesita que los derechos y libertades de los ciudadanos, se realicen en un marco de respeto y protección de sus garantías. 
Por lo tanto, es fundamental el respeto de los derechos humanos en el proceso penal. Sin derechos y garantías, el Estado democrático se pone en tela de juicio, y las actuaciones de los encargados de reconstruir el hecho, pueden caer en el autoritarismo e inquisición. De tal manera, se propone que el Estado mexicano otorgue a todas las personas sin excepción, un máximo de seguridad jurídica y un mínimo de violencia, mediante un proceso penal más garantista y acusatorio, para ello, es necesario quitar las reglas insertadas en el texto constitucional con la reforma de 2008 -recordando que toda constitución debe enunciar principios y no reglas- que describan todo lo relacionado a la delincuencia organizada, en específico, el tipo penal enunciado en la fracción novena del artículo dieciséis.

\section{Bibliografía}

Alexy, Robert. (2007). Teoría de los derechos fundamentales. ( $2^{\mathrm{a}}$ ed.). trad. Carlos Bernal Pulido, Madrid: Centro de Estudios Políticos y Constitucionales.

Andrés, Ibáñez, Perfecto. (2015) Los hechos en la sentencia penal. México: Fontamara.

Atienza, Manuel (2006). El Derecho Como Argumentación. Barcelona: Ariel.

Barragán, Salvatierra, Carlos. (2006). Derecho Procesal Penal. (3 ${ }^{\mathrm{a}}$ ed). México: Editorial McGraw.

Bassat Torres, Nelson. (2007). La duda razonable en la prueba penal con especial referencia a Puerto Rico. Bilbao: Servicio Editorial del País Vasco,.

Baytelman, Andrés y Duce, Mauricio. (2009). Litigación penal Juicio Oral y prueba. México: Editorial Fondo de Cultura Económica.

Bernal, Pulido, Carlos. (2011). El exceso de proporcionalidad: entre el exceso por acción y la insuficiencia por omisión o defecto, en Miguel Carbonell (coord.) Argumentación Jurídica. El juicio de ponderación y el principio de proporcionalidad. México: Porrúa. 
Cafferata Nores, José. (2008). La Prueba en el Proceso Penal, Argentina: Lexis-Nexis.

Ferrer, Jordi. (2007). La valoración racional de la prueba. España: Marcial Pons.

Ferrajoli, Luigi. (2004). Epistemología Jurídica y Garantismo. México: Fontamara.

Galindo, Sifuentes, Ernesto. (2010). La Valoración de la Prueba en los Juicios Orales. México: Flores Editores y Distribuidores.

González Salas Raúl. (2003). La presunción en la valoración de las pruebas. México: Inacipe.

Hidalgo, Murillo, José Daniel. (2009) Sistema Acusatorio Mexicano y Garantías del Proceso Penal, México: Porrúa.

Laudan, Larry (2013). Verdad, error y proceso penal, Un ensayo sobre epistemología jurídica, trad. de Carmen Vázquez y Edgar Aguilera. España: Marcial Pons.

Muñoz, Conde, Francisco. (2007). La búsqueda de la verdad en el proceso penal. ( $\left.3^{\mathrm{a}} \mathrm{ed}\right)$. Madrid: Hamurabi.

Natarén, Nandayapa, Carlos. (2011). Litigación Oral y práctica forense penal. México: Oxford.

Prigogine, Ilya. (1996). El fin de la certidumbre. Santiago de Chile: Editorial Andrés Bello.

Pastrana, Berdejo, Juan David y Benavente Chorres, Hesbert. (200). El juicio oral penal (Tecnicas y estrategias de litigación oral), México: Flores Editores.

Ribeiro, Toral, Gerardo. (2006). Verdad y Argumentación. México: Porrúa.

Rorty, Richard. (1996). Contingencia, ironía y solidaridad. Barcelona: Paidós.

Santacruz, Lima, Rafael (2015). La prueba en el sistema penal de excepción, México: Porrúa- Print.

Taruffo, Michele. (2011). La Prueba de los Hechos. (4 ed.). Madrid: Trotta. 